Int. J. Dev. Biol. 58: 799-809 (2014)

doi: $10.1387 / \mathrm{ijdb} .140215 \mathrm{ml}$

\title{
Left-right patterning in Xenopus conjoined twin embryos requires serotonin signaling and gap junctions
}

\author{
LAURA N. VANDENBERG ${ }^{1,2}$, DOUGLAS J. BLACKISTON ${ }^{1}$, ADAM C. REA ${ }^{3}$, TIMOTHY M. DORE ${ }^{3,4}$, \\ and MICHAEL LEVIN*,1 \\ ${ }^{1}$ Biology Department, Center for Regenerative and Developmental Biology, Tufts University, Medford, MA, USA, \\ ${ }^{2}$ Department of Public Health, Division of Environmental Health Sciences, University of Massachusetts - Amherst, Amherst, \\ MA, USA, ${ }^{3}$ Department of Chemistry, University of Georgia, Athens, GA, USA and \\ ${ }^{4}$ New York University Abu Dhabi, Abu Dhabi, United Arab Emirates
}

\begin{abstract}
A number of processes operating during the first cell cleavages enable the left-right (LR) axis to be consistently oriented during Xenopus laevis development. Prior work showed that secondary organizers induced in frog embryos after cleavage stages (i.e. conjoined twins arising from ectopic induced primary axes) correctly pattern their own LR axis only when a primary (early) organizer is also present. This instructive effect confirms the unique LR patterning functions that occur during early embryogenesis, but leaves open the question: which mechanisms that operate during early stages are also involved in the orientation of later-induced organizers? We sought to distinguish the two phases of LR patterning in secondary organizers (LR patterning of the primary twin and the later transfer of this information to the secondary twin) by perturbing only the latter process. Here, we used reagents that do not affect primary LR patterning at the time secondary organizers form to inhibit each of 4 mechanisms in the induced twin. Using pharmacological, molecular-genetic, and photo-chemical tools, we show that serotonergic and gap-junctional signaling, but not proton or potassium flows, are required for the secondary organizer to appropriately pattern its LR axis in a multicellular context. We also show that consistently-asymmetric gene expression begins prior to ciliary flow. Together, our data highlight the importance of physiological signaling in the propagation of cleavage-derived LR orientation to multicellular cell fields.
\end{abstract}

KEY WORDS: ion flux, polarity, heterotaxia, drug screen, connexin, twinning, asymmetry, gap junction

\section{Introduction}

After fertilization, one of the key milestones of embryogenesis is the establishment of the primary body axes. Developmental biologists have long been intrigued by the mechanisms responsible for orienting the left-right (LR) axis, which is defined with respect to the anterior-posterior and dorsal-ventral axes (Brown and Wolpert, 1990; Tabin, 2011). Although the vast majority of vertebrate species display LR-symmetrical external body plans, these animals have consistent asymmetries in the position and shape of the internal organs including the heart, stomach, gall bladder, spleen, and brain (Palmer, 1996; Palmer, 2004; Aw and Levin, 2008). Birth defects that disrupt LR patterning affect about 1 in 6000 live births, but are often accompanied by severe medical consequences, particularly when LR placement of individual organs in the body is randomized, a condition referred to as heterotaxia (Casey and Hackett, 2000; Hackett, 2002; Peeters and Devriendt, 2006; Cohen et al., 2007).

The establishment and orientation of the LR axis requires 3 distinct steps that take place at progressively later stages of development: symmetry breaking, when the two sides of the embryo first become different and the nascent LR axis is consistently aligned with respect to the other 2 body axes; the conversion of these asymmetries to LR-biased expression of genes such as the Nodal-Lefty-Pitx cassette; and the translation of this asymmetric gene expression into asymmetric morphology and position of organs (Basu and Brueckner, 2008; Blum et al., 2009; Vandenberg and

Abbreviations used in this paper: 5-HT, serotonin; ABP, amine-binding protein; GJC, gap junctional communication; LR, left-right.

\footnotetext{
*Address correspondence to: Michael Levin. Biology Department, Center for Regenerative and Developmental Biology, Tufts University, 200 Boston Avenue, Suite 4600, Medford, MA 02155-4243, USA.Tel: +1-617-627-6161. E-mail: michael.levin@ tufts.edu
}

Supplementary Material for this paper is available at: http://dx.doi.org/10.1387/ijdb.140215ml

Accepted: 12 September 2014. Final, author-corrected PDF published online: 3 October 2014

ISSN: Online 1696-3547, Print 0214-6282 
TABLE 1

PHARMACOLOGICAL REAGENTS TESTED IN SINGLETON EMBRYOS ${ }^{a}$

\begin{tabular}{|c|c|c|c|c|c|c|c|}
\hline \multirow[b]{3}{*}{ Treatment } & \multirow[b]{3}{*}{ Target } & \multicolumn{6}{|c|}{ Exposure period } \\
\hline & & \multicolumn{3}{|c|}{1 cell - neurula } & \multicolumn{3}{|c|}{ St 8 - neurula } \\
\hline & & $\mathbf{n}$ & $\%$ heterotaxia & $\%$ inverted hearts & $\mathrm{n}$ & $\%$ heterotaxia & $\%$ inverted hearts \\
\hline Lindane $(2 \mu \mathrm{M})$ & GJC & 116 & 21 & 12 & 237 & 1 & 0 \\
\hline Tropisetron $(10 \mu \mathrm{M})$ & $5-\mathrm{HT}$ & 84 & 23 & 16 & 150 & 3 & 2 \\
\hline $\mathrm{BaCl}(10 \mathrm{mM})$ & $\mathrm{K}^{+}$ & 82 & 23 & 16 & 127 & 3 & 1 \\
\hline $\mathrm{pH} 4.0$ & $\mathrm{H}^{+}$ & 247 & 32 & 24 & 202 & 3 & 2 \\
\hline Fluoxetine $(0.8 \mu \mathrm{M})$ & 5-HT & 84 & 36 & 25 & 79 & 1 & 0 \\
\hline
\end{tabular}

aThese reagents were tested in singleton embryos either early ( 1 cell - neurula) or late (stage 8 - neurula), to identify reagents that could be used in conjoined twins.

Levin, 2010b; Burdine and Caspary, 2013; Vandenberg and Levin, 2013). Although the last two phases are fairly well understood and are generally considered not controversial, there remain many questions about the earliest steps in symmetry breaking.
A
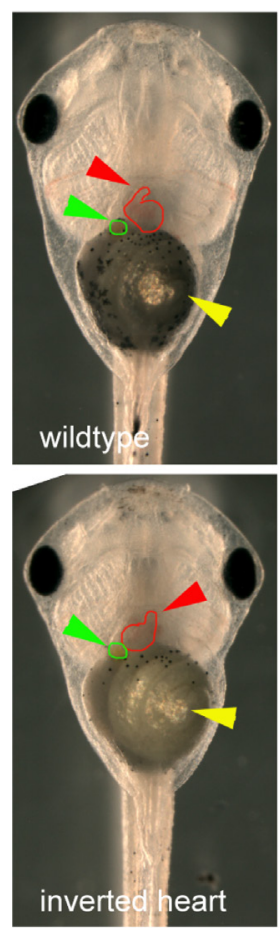

B
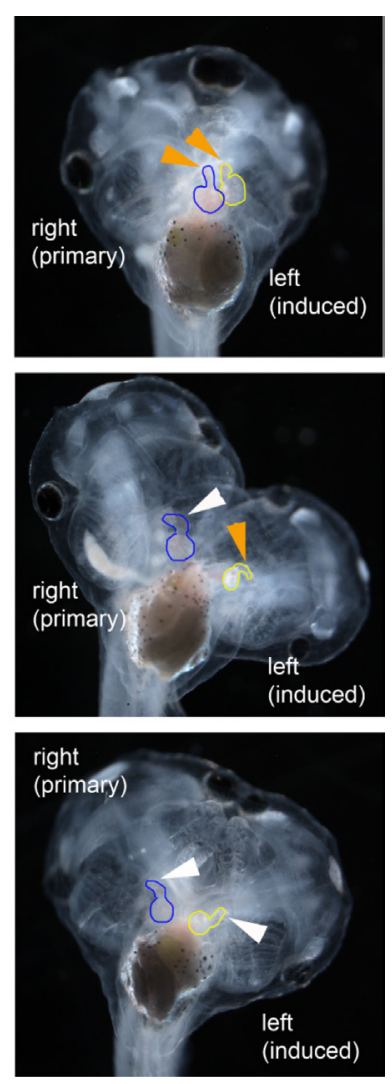

In Xenopus embryos, LR asymmetries are observed during early cleavage stages due to the presence of a consistently biased, chiral cytoskeleton (Bunney et al., 2003; Danilchik et al., 2006; Aw et al., 2008; Lobikin et al., 2012b). The chiral cytoskeleton (and possibly differential chromatid segregation (Klar, 1994;Armakolas and Klar, 2007; Klar, 2008; Armakolas et al., 2010; Sauer and Klar, 2012)) drives the asymmetric distribution of proteins including $\mathrm{K}^{+}$channels and $\mathrm{H}^{+}$pumps, which become more strongly localized to the ventral right blastomere (Levin et al., 2002; Adams et al., 2006; Morokuma et al., 2008; Aw et al., 2010). The biased localization of these ion transporters establishes consistent LR differences in the $\mathrm{pH}$ and transmembrane voltage on the left and right sides of the embryo. The asymmetric efflux of positively charged ions establishes a bioelectrical gradient, with the ventral right blastomere more negatively charged; this gradient drives further asymmetric distribution of small charged molecules such as serotonin (5-HT) via a series of open gap junctions connecting across a circumferential path throughout the dorsal portion of the embryo (Levin and Mercola, 1998; Fukumoto et al., 2003; Fukumoto et al., 2005b). Serotonin's accumulation in the cells to the right of the ventral gap-junctional boundary epigenetically represses the expression of the nodal homolog Xnr-1 via a Mad3-HDAC1 receptor complex, resulting in the lack of expression of this gene on the right side of the body (Carneiro et al., 2011; Vandenberg et al., 2013b). Ciliary motion during late gastrula and early neurula stages also feeds into the expression of laterality genes (Vick et al., 2009).

Although many aspects of the intracellular asymmetry pathway have been demonstrated to be conserved in other species including chick, snails, Drosophila, zebrafish, and even single mammalian cells (reviewed in Levin, 2006; Vandenberg et al., 2013a), the Xenopusembryo has an advantage in that the earliest steps in the LR pathway normally occur when there are only a small number of blastomeres present, and these blastomeres are in direct contact with each other (Levin, 2003). Can these same mechanisms operate to establish LR asymmetry in embryos with vastly different body plans, including in embryos that orient the LR axis when hundreds or thousands of cells are present? The Xenopus conjoined twin model (Nascone and Mercola, 1997) offers an experimental system where the molecular genetic tools useful in identifying early determinants in the LR pathway are available, but where a more complex body plan can be probed. Conjoined twins can be induced by introducing molecular elements of Spemann's organizer, such as the 
transcription factor $X$ Siamois, to the developing embryo at a position 180 degrees across from the native organizer. Twins induced by this method only form after the mid-blastula transition, when zygotic transcription commences, enabling the induced secondary twin model to provide information about the mechanisms orienting a new primary axis when each cell is only a small portion of the whole body - a much different topology than the holoblastic cleavage of the original frog embryo.

Numerous studies have used the conjoined twin to probe late mechanisms for establishing LR asymmetry (Nascone and Mercola, 1997; Vandenberg and Levin, 2010a; Beyer et al., 2012; Vandenberg and Levin, 2012). Prior work revealed that organizers induced past the first few cleavages can only orient the LR axis correctly when an original axis (the primary twin) is already present elsewhere in the embryo (Vandenberg and Levin, 2010a). This is the "big brother effect", in which late-induced twins must pick up LR orientation information from original organizers. Planar cell polarity and apical basal polarity proteins are required for this instructive process (Vandenberg and Levin, 2012). The need for an organizer that had the benefit of early cleavage mechanisms for their LR determination to enable a later organizer to properly orient itself highlights the importance of early cleavage events, which are essential for correct LR orientation.

It is not known how many of the mechanisms by which early chiral information is converted into multicellular asymmetric gene expression are operational during late organizer induction. Here, we have used the conjoined twin model to determine whether the mechanisms that operate during early cleavage stages also participate in orienting the LR axis when an organizer arises de-novo in a multi-cellular field. Our results, using reagents that do not affect asymmetry processes in a primary organizer at the time at which the secondary twin is forming, reveal that some, but not all, of these mechanisms are indeed required to orient the LR axis in the context of thousands of cells. Moreover, we report that transcriptional asymmetries are established prior to the initiation of ciliary flow, confirming the unique functions of the earliest stages of development for LR asymmetry.

\section{Results}

\section{Chemical agents disrupt LR patterning in singletons early, but not late}

Inverse drug screens (and the subsequent gene-specific validations) have previously implicated $\mathrm{K}^{+}$channels, $\mathrm{H}^{+}$ pumps, gap junctional communication (GJC) and serotonin $(5-\mathrm{HT})$ in the early orientation of the LR axis in Xenopus (Adams and Levin, 2006). We first tested reagents that target these mechanisms in singleton embryos, to confirm which ones randomized asymmetry (Fig. 1) when used early (exposure starting at 1-cell) but did not disrupt LR patterning when exposures start at blastula stage (stage 8). We specifically wanted to identify reagents that are effective early but not later, so that we could use them to probe the mechanisms of secondary organizer LR patterning without concerns that they would interfere with any laterality functions of the primary organizer (Fig. 2). We identified treatments for

B

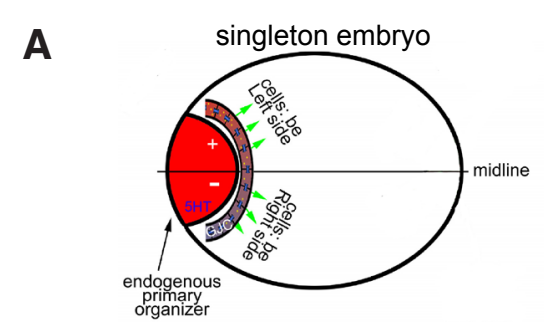

LR-patterning effects: start at 1 cell

"big brother instruction": none

all four targets ( $\mathrm{K}^{+}$channels, $\mathrm{H}^{+}$pumps, GJC and 5-HT signaling) that disrupted LR patterning in singletons when used early, but not later (Table 1). These reagents were then used to determine

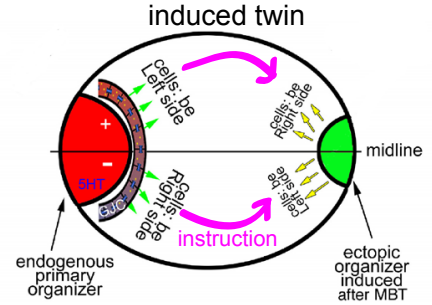

start at 1 cell in primary organizer start at stage 8 in ectopic organizer

after ectopic organizer is induced (stage 8)
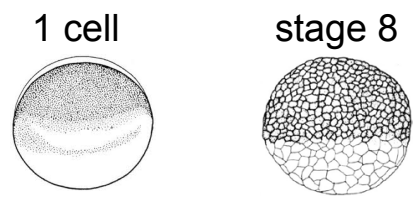

neurula

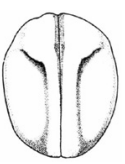

early exposures (1 cell - neurula): targets primary organizer, expect randomized organ situs

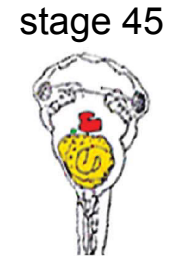

NEED: heterotaxia

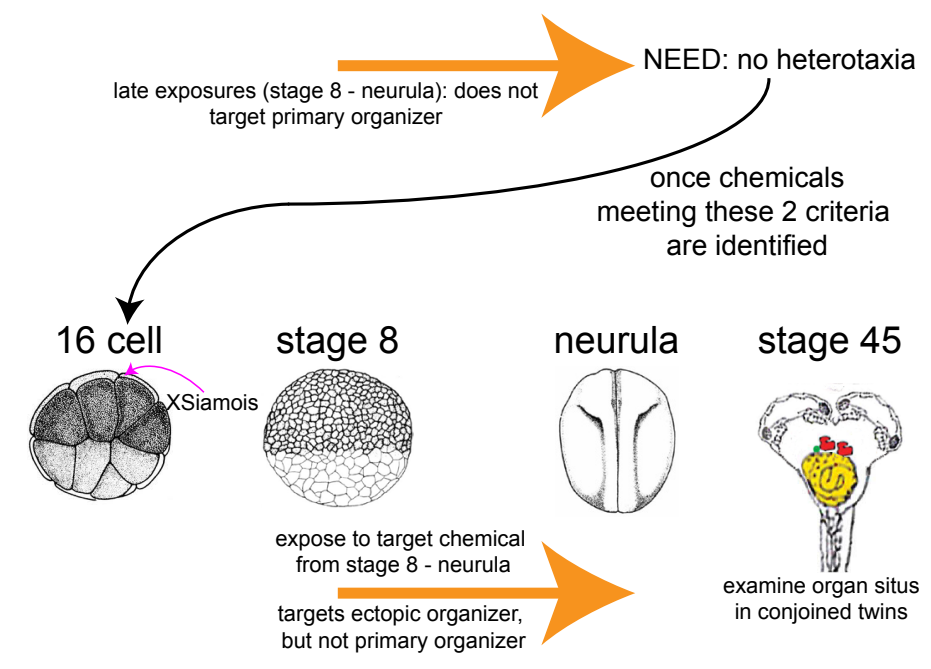

Fig. 2. Schematic for general experimental design. (A) There are two distinct phases in the orientation of the $L R$ axis in conjoined twins: the patterning of the primary twin (starting at 1-cell, where some cells are instructed to "be left side" or "be right side") and the transferring of information via "the big brother effect" to the induced (ectopic) organizer (starting at stage 8, where cells in the conjoined twin must receive new information about whether they are located on the left or right side). We sought reagents that would perturb only the latter process. (B) This schematic describes our experimental approach. As indicated by NEED, we sought chemical reagents that disrupt $L R$ patterning in singleton embryos when treatments occur from 1-cell through early neurula stages (blue arrow), but not when treatments were limited to later stages (stage 8 through neurula stages, orange arrow). Results of these experiments are reported in Table 1. We then induced conjoined twins at the 8-or 16-cell stage, and treated these embryos with the identified reagents from stage 8 through neurula stages, to determine whether we could disrupt the second phase of $L R$ axis orientation in conjoined twins. Organ situs was examined at stage 45. 
whether their targets were also utilized in LR patterning of a secondary organizer occurring in the context of an existing blastula.

\section{Disrupting $\mathrm{H}^{+}$or $\mathrm{K}^{+}$signaling does not affect $L R$ patterning in conjoined twins}

Singleton embryos incubated at $\mathrm{pH} 4.0$ starting from the 1-cell stage have randomized LR patterning because such low extracellular $\mathrm{pH}$ interferes with the normal proton efflux from right side cells (Levin et al., 2002; Adams et al., 2006; Aw et al., 2008); however,

A

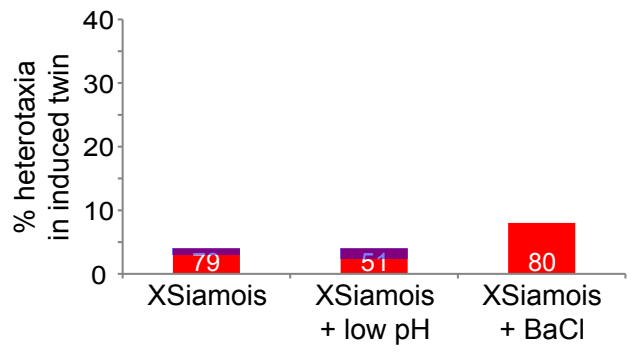

B

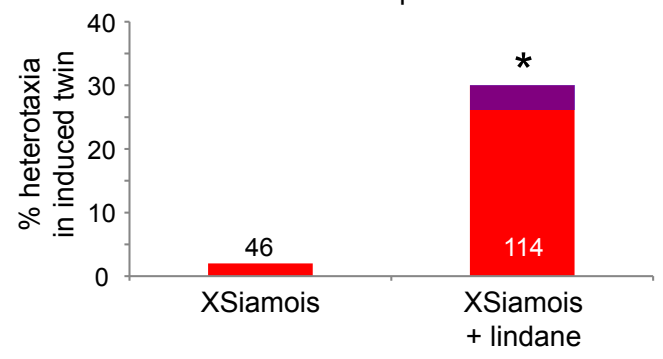

C

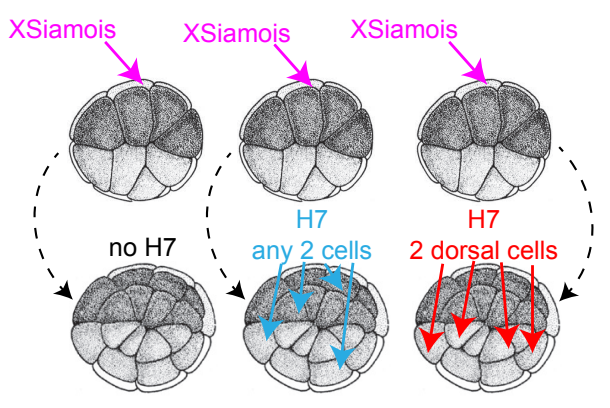

D

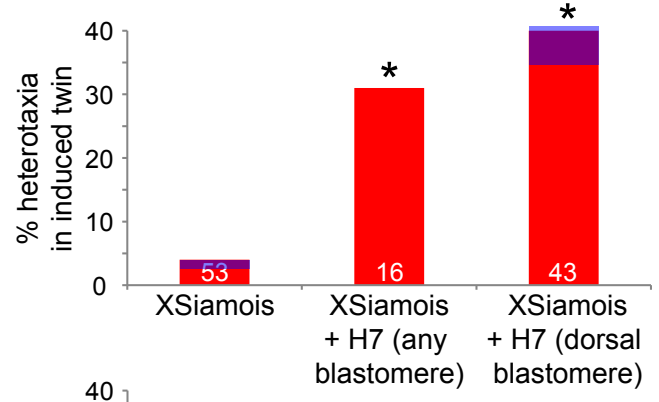

E

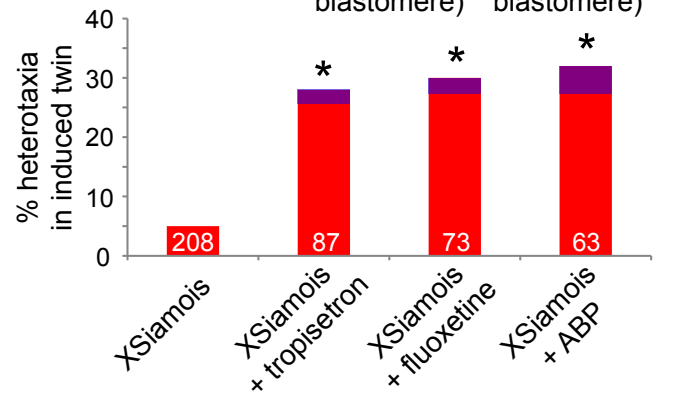

incubations in $\mathrm{pH} 4.0$ medium that start at stage 8 have no effect on LR patterning in singletons (Table 1), confirming this procedure as targeting only very early phases of LR asymmetry. To test the impact of altered $\mathrm{H}^{+}$signaling on LR patterning in conjoined twins, embryos were injected with XSiamois and then incubated in $0.1 \mathrm{X}$ MMR, pH 4.0 starting from stage 8 . We found no effect of low $\mathrm{pH}$ MMR on the incidence of heterotaxia in the induced twin (Fig. 3A), suggesting that $\mathrm{H}^{+}$efflux is not necessary for proper LR orientation of a primary axis initiated at later stages.

Similarly, singleton embryos incubated in 4-40 $\mathrm{mM} \mathrm{BaCl}$ have randomized LR axes when treatments start at the 1-cell stage (due to blockade of potassium channels), but normal LR development when exposures begin at stage 8 (Table 1). To test the effects of altered $\mathrm{K}^{+}$signaling on LR patterning in conjoined twins, twins were induced by XSiamois and embryos were treated with $\mathrm{BaCl}$ starting from stage 8 . Altered LR patterning was not observed in the induced twin axes (Fig. 3A), indicating that $\mathrm{K}^{+}$signaling is also not required for LR patterning of primary axes induced at later stages. We conclude that the process by which secondary organizers derive $\mathrm{LR}$ information utilizes neither $\mathrm{K}^{+}$nor proton effluxes.

Pharmacological and molecular genetic loss-of-function as-
says implicate GJC in LR patterning in late-induced organizers

We next examined the role of gap junctional communication. Singleton embryos treated with lindane (a gap junction blocker (Guan and Ruch, 1996; Li and Mather, 1997; Levin and Mercola, 1998)) starting from the 1-cell stage exhibited randomized LR patterning, but incubations that started at stage 8 had no effect on LR patterning in singletons (Table 1). To test the role of GJC in LR patterning of conjoined twins, embryos were injected with XSiamois to induce left-sided twins and then incubated in lindane starting from stage 8 . In contrast to what was observed for treatments targeting $\mathrm{H}^{+}$and $\mathrm{K}^{+}$signaling, disruption of GJC via treatment with lindane induced heterotaxia in 30\% of the induced twins (Fig. 3B).

To confirm this pharmacological result with a gene-specific molecular reagent, embryos were injected with XSiamois and $\mathrm{H} 7 \mathrm{mRNA}$, a dominant negative form of a chimeric connexin that efficiently disrupts GJC in Xenopus (Paul et al., 1995; Levin and Mercola, 1998). When H7 mRNA was introduced into two distinct

Fig. 3. Gap junctional communication (GJC) and 5- $\mathrm{HT}$, but not $\mathrm{K}^{+}$or $\mathrm{H}^{+}$ flux, are required for LR asymmetry in conjoined twins. (A) Neither low $\mathrm{pH}$, which inhibits $\mathrm{H}^{+}$efflux pumps, nor $\mathrm{BaCl}$, which blocks all $\mathrm{K}^{+}$channels, disrupts $L R$ patterning in late-induced twins when exposures start late. (B) Late treatment with lindane, which disrupts GJC, induces heterotaxia in conjoined twins. (C) A schematic detailing experiments with H7 mRNA, a dominant negative form of a chimeric connexin that disrupts GJC. All embryos were injected with XSiamois at the 8- or 16-cell stage. One set was injected with $\mathrm{H} 7$ into any two blastomeres in the top two tiers of the animal pole at the 32-cell stage. Another set was injected with $\mathrm{H} 7$ into any two dorsal blastomeres in the top two tiers of the animal pole at the 32-cell stage. (D) Disruption of GJC with H7 mRNA alters LR patterning in late-induced organizers, even when GJC is only disturbed in the dorsal cells; the dorsal cells contribute to the primary axis and not the induced twin. (E) Altered 5-HT signaling at late stages disrupts LR patterning in conjoined twins. In all panels, the numbers on the graphs indicate the sample size, ${ }^{*} p<0.05$ compared to untreated controls, Chi Square test. Red bars indicate inverted hearts, blue indicates inverted stomach and/ or gall bladder, and purple indicates inverted heart plus stomach and/or gall bladder. 
blastomeres anywhere in the top two tiers of the animal pole (Fig. $3 C), 31 \%$ of induced twins that were produced from these treatments exhibited randomized heart situs (Fig. 3D). To determine whether proper GJC was needed in the blastomeres that would contribute to the primary organizer, $\mathrm{H} 7$ was targeted only to two dorsal blastomeres (Fig. 3C). Again, the induced twins had randomized LR axes (Fig. 3D). These results indicate that GJC is required to achieve proper LR patterning in conjoined twins, suggesting that connexin-mediated communication plays a role in the orientation of the LR axis of late-induced organizers (Vandenberg and Levin, 2012).

\section{Disruption of 5-HT signaling alters LR patterning in conjoined twins}

Singleton embryos treated with $10 \mu \mathrm{M}$ tropisetron, a 5-HT receptor 3 antagonist (Kutz, 1993; Monge et al., 1993), had randomized LR patterning when exposures started at the 1-cell stage but not when exposures started at stage 8 (Table 1). To test the effect of altered 5-HT signaling on LR patterning in conjoined twins, embryos were injected with XSiamois and then incubated in 10 $\mu \mathrm{M}$ tropisetron starting from stage 8 . The induced twins exposed to the drug exhibited significant increases in inverted heart situs compared to twins that were not exposed to tropisetron (Fig. 3E). Similarly, singleton embryos treated with $15 \mu \mathrm{M}$ fluoxetine, a selective 5-HT reuptake inhibitor that alters the amount of available intracellular 5-HT (Fukumoto et al., 2005a), had randomized LR asymmetry only when exposures occurred early (Table 1). When induced conjoined twins were exposed to fluoxetine starting from stage 8, there was a significant increase in heterotaxia (Fig. 3E). These results implicate serotonergic signaling specifically in the LR patterning of late-induced organizers.

To verify these pharmacological loss-of-function results with molecular genetic specificity, 8-or 16-cell embryos were co-injected with XSiamois and mRNA encoding amine binding protein (ABP), a protein that binds, sequesters and inactivates 5-HT (Andersen et al., 2003; Fukumoto et al., 2005b). When 5-HT signaling was specifically reduced in the blastomeres that contributed to the induced twin, heterotaxia was observed (Fig. 3E). These results validate the pharmacological data, and indicate that 5 -HT signaling is required for proper orientation of the LR axis in the complex body plan of the conjoined twin.

Fig. 4. Caged serotonin molecules implicate 5-HT in LR patterning of a secondary organizer. (A) In singleton embryos, injection of the caged molecule (BHO-O-5HT) at the 1-cell stage, paired with uncaging at the 32-cell stage, induces significant levels of heterotaxia. Photoactivation of 5-HT at the 8-cell stage did not significantly increase rates of $L R$ patterning defects. (B) BHQ-O-5HT was injected at the 1-cell stage and conjoined twins were induced at the 8- or 16-cell stage. When 5-HT was uncaged at the 32-cell stage, prior to the induction of conjoined twins, LR patterning in the induced twin was randomized. When 5-HT was uncaged at stage 8 , as XSiamois begins to induce the development of a conjoined twin, $L R$ patterning defects were still observed. (C) BHO-O-5HT and XSiamois were co-injected in the ventral vegetal left blastomere at the 8-or 16-cell stage, and 5-HT was uncaged at either 32-cell, stage 8, or stage 10. Regardless of when the 5-HT was released, heterotaxia in the induced twin was observed. In all panels, the numbers on the graphs indicate the sample size, ${ }^{*} p<0.05$ compared to embryos injected with BHO-O-5HT but not uncaged, Chi Square test. Red bars indicate inverted hearts, blue indicates inverted stomach and/or gall bladder, and purple indicates inverted heart plus stomach and/or gall bladder.
To better probe the spatial and temporal role of 5-HT in LR patterning in conjoined twins, we employed a caged 5-HT molecule, $\mathrm{BHQ}-\mathrm{O}-5 \mathrm{HT}$, which releases $5-\mathrm{HT}$ after molecular uncaging via exposure to light (Rea et al., 2013). Releasing 5-HT from BHQ$\mathrm{O}-5 \mathrm{HT}$ at the 32-cell stage randomizes the LR axis in singleton embryos, but uncaging at stage 8 has no significant effect on the LR axis of singletons (Fig. 4A), confirming this as a reagent that can be used to specifically target the instructive phase of organizer patterning. To further probe the temporal role of $5-\mathrm{HT}$ in LR patterning of late-induced organizers, $\mathrm{BHQ}-\mathrm{O}-5 \mathrm{HT}$ was injected into the apical-most point of the 1-cell embryo, followed by injection

A
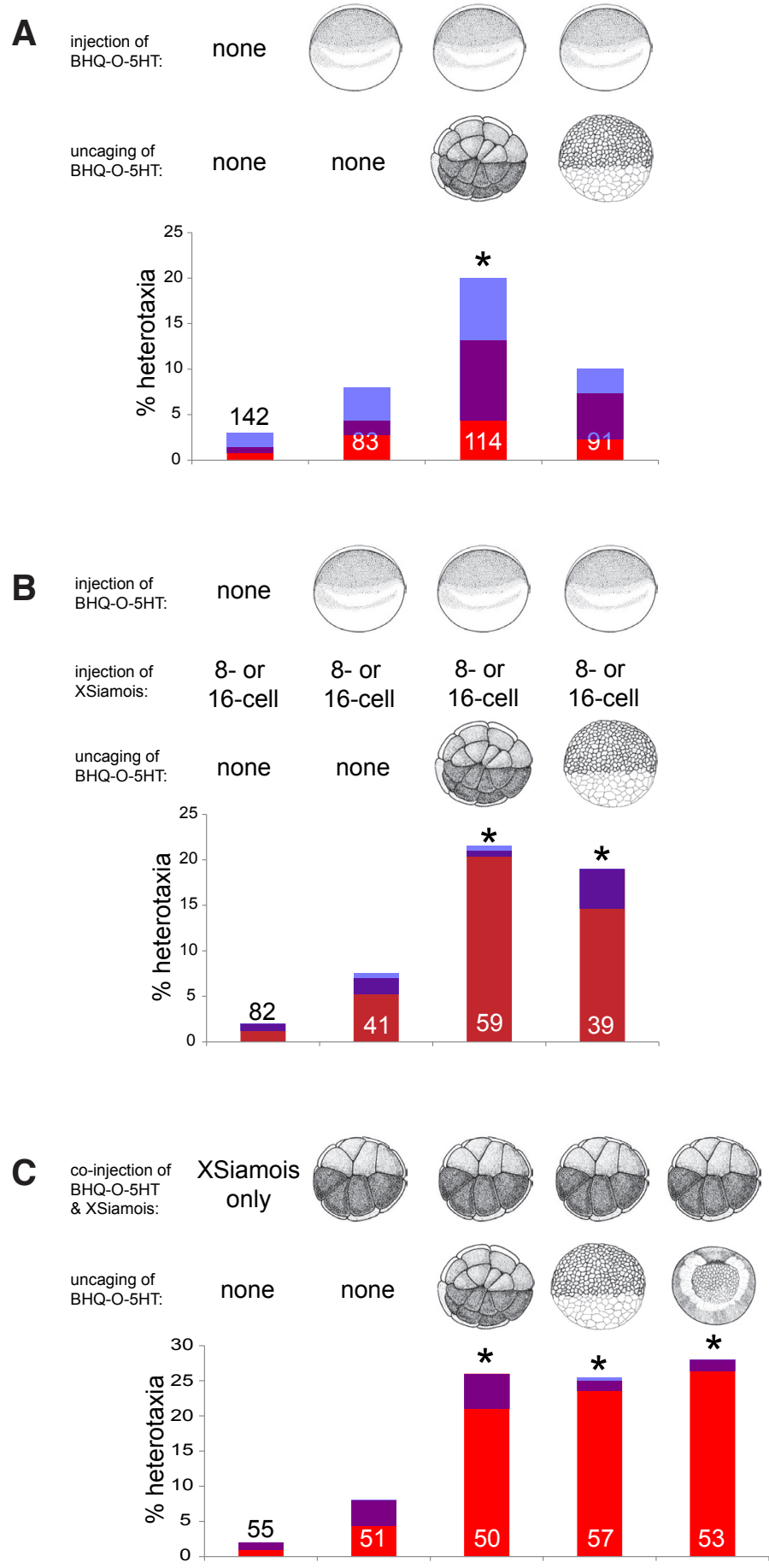

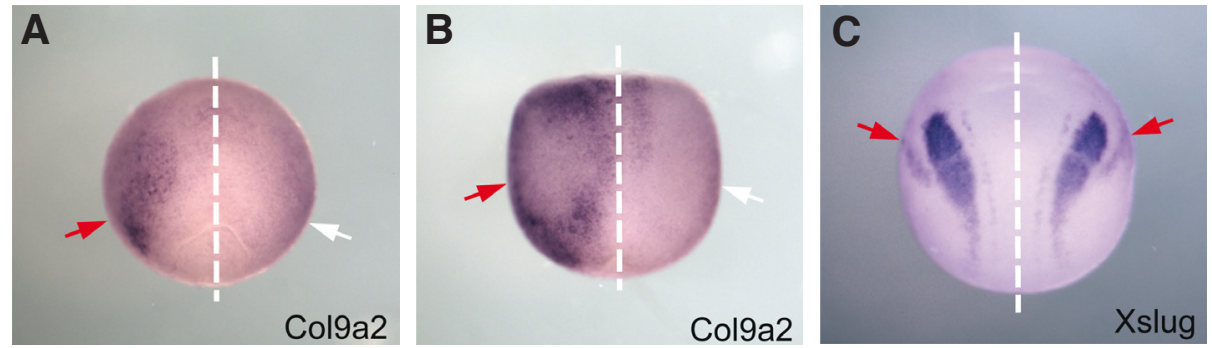

Fig. 5. In situ hybridization for collagen9a2 confirms the microarray result of left sided expression prior to nodal flow. (A) Embryos processed by in situ hybridization for the marker col9a2 show expression only on the left side or (B) on both sides but with a strong left bias. Embryos were examined prior to the development of ciliary flow. (C) Control embryos probed for the marker Xslug, which was not biased in the microarray results, showed bilateral symmetric expression in all animals examined. Red arrows indicate areas of expression; white arrows indicate absence of expression. The dotted line demarcates the embryo's midline. All panels show a dorsal view, with the anterior pointing upward.

with XSiamois at the 8- or 16-cell stage to induce conjoined twins. When $\mathrm{BHQ}-\mathrm{O}-5 \mathrm{HT}$ was activated at the 32-cell stage, LR defects were observed in conjoined twins, similar to what was observed in singletons (Fig. 4B). When 5-HT was photochemically released beginning at stage 8 , relatively high rates of heterotaxia were observed in conjoined twins, a contrast to the normal LR axes typical of singletons treated in the same way (Fig. 4B). A second subset of embryos was co-injected with $\mathrm{BHQ}-\mathrm{O}-5 \mathrm{HT}$ and XSiamois, limiting the localization of the caged 5-HT molecule to the cells that would contribute to the induced twin. When 5-HT was released at either 32-cell or at stage 8, significant levels of heterotaxia were observed in the induced twin (Fig. 4C). Even uncaging as late as stage 10 was able to randomize LR patterning in conjoined twins (Fig. 4C). In summary, results using this novel reagent provided temporal control to probe the role of 5-HT throughout the embryo or in just those blastomeres that contributed to the induced twin. This caged 5-HT molecule revealed a role for 5-HT in orienting the LR axis of the late-induced conjoined twin, and specifically implicate this molecule during late stages as the induced twin begins to develop with the onset of zygotic transcription.

\section{Identification of novel LR-biased transcripts in the developing embryo}

Our data demonstrate that GJC and 5-HT play a role in the LR specification of conjoined twins. Prior results indicated that serotonergic signaling through intracellular (gap-junctional) paths impinged on asymmetric Nodal transcription through epigenetic repression mediated by the Mad3-HDAC1 complex (Carneiro et al., 2011). However, many hours separate the activity of the serotonin/GJC system from the eventual left-sided expression of Nodal. What transcriptional events may underlie LR patterning downstream of serotonergic signaling but prior to late steps such as ciliary function and Nodal expression? To identify mRNAs that are asymmetrically expressed during this developmental period (i.e. after cleavage stages but prior to the onset of ciliary flow), we performed a preliminary microarray analysis comparing gene expression levels between the (pooled, $N=50$ ) right and left sides of stage 13 Xenopus embryos (prior to GRP function which begins at stages 14-15). Out of approximately 29,000 transcripts represented in the array, about $1.3 \%$ were known genes with a significant bias. We identified 33 genes with at least a 2-fold higher expression level on the left side of the embryo, 314 with at least a 2-fold higher expression level on the right side of the embryo, 6 transcripts which were detectable only on the left side, and 48 transcripts which were detectable only on the right side (Supplemental Table 1). While functional roles for these targets in LR asymmetry remain to be tested, the data reveal clear asymmetries in transcriptomic profile of the $L$ and $R$ sides before ciliary flow begins. It should be noted that the data contain novel targets, as well as those implicated by prior work in the LR asymmetry field in a number of species, such as Sonic hedgehog (Levin et al., 1995), collagen (Trelstad and Coulombre, 1971; Heacock and Agranoff, 1977; Bergmann et al., 1998), and dynein (Supp et al., 1997; Armakolas and Klar, 2007).

While microarray measurements are inherently more sensitive than the non-quantitative chromogenic in situ hybridization that is often used to look for asymmetric gene expression, we did examine the expression of one gene of interest, the most highly-expressed Left-only mRNA (collagen9A2) by whole mount in situ hybridization (WISH) analysis at stage 12 and 13. This transcript was also of particular interest because collagen is known to be regulated by both serotonergic signaling (Highton and Garrett, 1963; Kasho et al., 1998) and gap junction-mediated signaling (Moyer et al., 2004; Ehrlich et al., 2006). The WISH results corroborated the microarray data, revealing expression only on the left side of the embryo $(n=14)$ or with an extremely strong left bias $(n=4)$ (Fig. 5 A,B). As a negative control we also used an anti-sense probe for XSlug, a gene that was not identified as left-right biased in in the microarray, and saw the expected symmetric expression in all embryos ( $n=36$, Fig. 5C). Taken together, these results identify a number of additional candidate targets to be functionally tested downstream of the serotonergic and gap junctional communication system in Xenopus, and reveal that asymmetric transcription already exists prior to ciliary flow.

\section{Discussion}

Xenopus has proven to be a valuable model to understand the mechanisms responsible for orienting the LR axis due to the plethora of molecular-genetic reagents available, their ease of use for pharmaceutical exposures, the availability of large numbers of embryos, and their well-characterized cell lineages (Yost, 1998; Aw and Levin, 2008; Blum et al., 2009). In fact, a large number of studies using pharmacological and molecular genetic loss-offunction reagents have helped to elucidate the steps involved in orienting the LR axis in this species (Yost, 1990; Hyatt and Yost, 1998; Levin and Mercola, 1998; Kramer et al., 2002; Levin et al., 2002; Bunney et al., 2003; Fukumoto et al., 2003; Chen et al., 2004; Fukumoto et al., 2005a; Fukumoto et al., 2005b; Adams et al., 2006; Danilchik et al., 2006; Oviedo and Levin, 2007; Aw et al., 2008; Morokuma et al., 2008; Aw et al., 2010; Carneiro et al., 2011; Lobikin et al., 2012b; Vandenberg and Levin, 2012; Vandenberg et al., 2013b; Vandenberg et al., 2013c). These steps include a chirally biased cytoskeleton, ion transporters, gap junctions, and serotonin (Vandenberg and Levin, 2010b) as well as downstream 
steps such as ciliary flow that likely serve to maintain asymmetries established in early cleavage stages (Schweickert et al., 2007; Beyer et al., 2012; Walentek et al., 2012).

Previous studies have used the conjoined twin model to investigate the timing of events required for orientation of the LR axis in such a complex body plan. Twins can be induced by injections of mRNAs encoding transcription factors such as XSiamois, which initiate secondary axes only after MBT (stage 8), when zygotic transcription begins. One of the first studies to examine Xenopus twins observed that induced twins have proper LR patterning when localized on the left side of the body (Nascone and Mercola, 1997); the twin on the right is randomized due to cross-over of secreted Shh, Nodal, and Activin signaling at very late stages (post neurulation) (Levin et al., 1996). Nascone and Mercola proposed that late organizers, induced when thousands of cells were present, could circumvent the early intracellular events that have been implicated in LR patterning and correctly initiate asymmetry (Nascone and Mercola, 1997). Yet additional studies revealed that this was not the case: late-induced organizers could only orient the LR axis in the context of a primary organizer (i.e. only as a twin); late-induced organizers introduced into embryos lacking LR patterning information, due to the blockage of cortical rotation, developed heterotaxia (Vandenberg and Levin, 2010a).

Our goal was to identify which mechanisms that are used in early LR patterning can also be used by late organizers induced in a multi-cellular context. To achieve this, we used perturbations that affect the patterning of the $2^{\text {nd }}$ organizer after stage 8 (blastula) but specifically do not affect LR patterning processes in the primary embryo at this time-point (Fig. 2). Our results using pharmacological and molecular-genetic reagents revealed that proton and potassium transport are dispensable (Fig. 3A), but GJC and 5-HT are both necessary for LR patterning in conjoined twins (Fig. $3 \mathrm{~B}, \mathrm{D}, \mathrm{E})$. Importantly, heart situs in the primary twin was randomized to a similar degree in all treatment groups (data not shown); Nascone \& Mercola reported this same phenomenon in their original experiments of conjoined twins, and determined that this was due to the late action of leaky morphogens from the induced twin (Levin and Nascone, 1997; Nascone and Mercola, 1997).

Our results also reveal a novel instructive role for $5-\mathrm{HT}$ during late axis specification. It was recently suggested that 5-HThas permissive roles in the formation of ciliated tissues during GRP formation (Beyer et al., 2012), acting as a competence factor rather than having an instructive role during orientation of the LR axis. This hypothesis is contradicted by prior (Fukumoto et al., 2005a; Fukumoto et al., 2005b; Adams et al., 2006; Carneiro et al., 2011) and more recent (Vandenberg et al., 2013b) work which clearly demonstrates an early instructive role for 5-HT, long before the appearance of cilia, and in blastomeres that do not contribute to ciliated flow. Further, the non-specific patterning effects observed in the study of 5-HT in the context of ciliated structures (Beyer et al., 2012) were never seen in our experiments.

Our data also reveal roles for GJC in LR asymmetry of lateinduced organizers. Studies of other species that orient their LR axis when thousands of cells are present have similarly revealed roles for GJC and 5-HT in LR asymmetry (Levin and Mercola, 1999; Fukumoto et al., 2005b; Muders et al., 2006). We propose a model for how LR asymmetry can be established in embryos with complex, multicellular cell fields. In this model, polarity proteins align the cells of the developing blastoderm, providing each cell with LR-orientation relative to the anterior-posterior and dorsalventral axis (Fig. 6). These polarity proteins also enable a series of gap junctions to be oriented within the blastoderm, which permits the biased transport of small signaling molecules including 5-HT between the original organizer and twin (Fig. 6B). We propose two plausible roles for $5-\mathrm{HT}$ in this complex body plan. The first

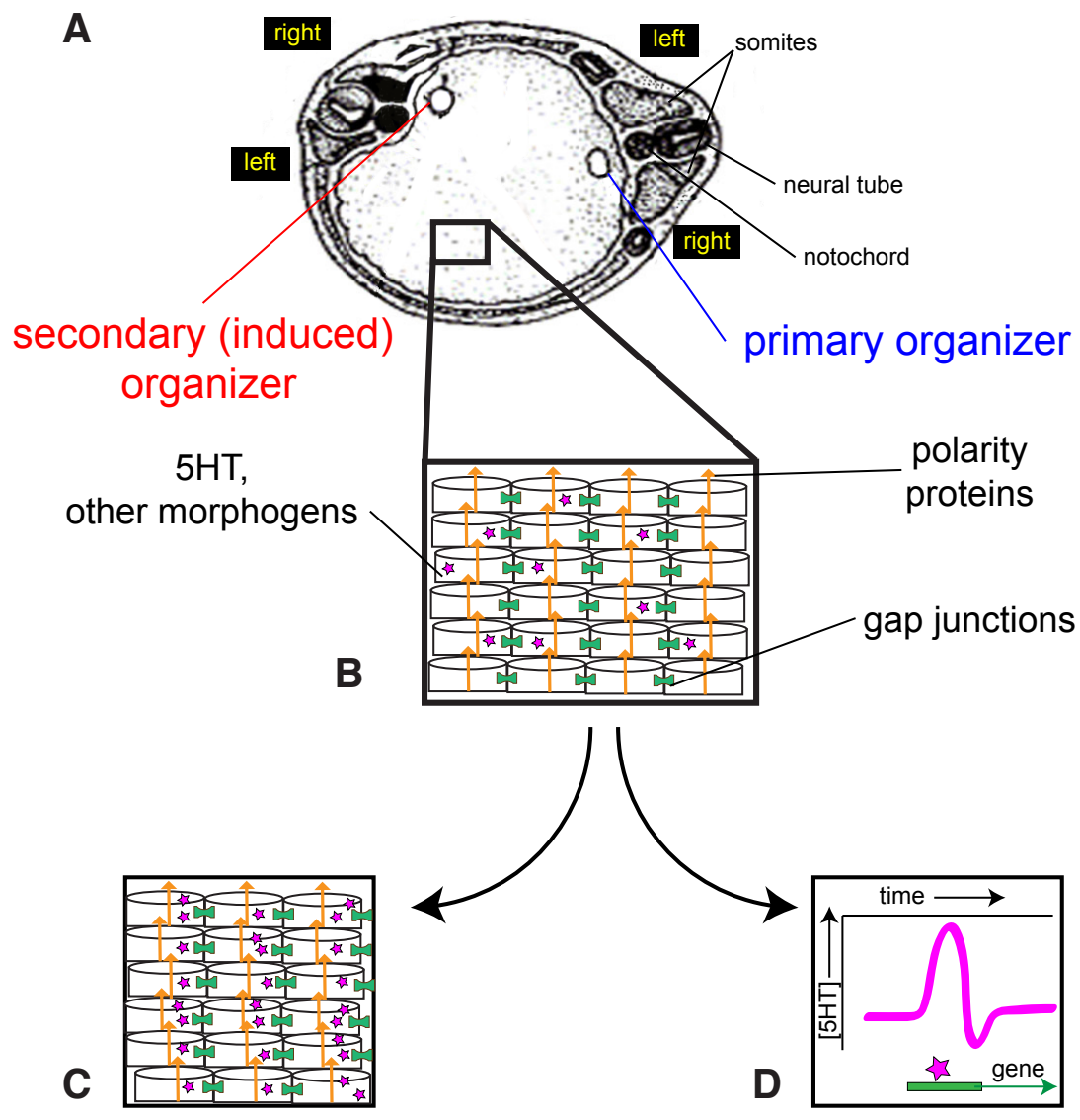

Fig. 6. A model for LR asymmetry in conjoined twins. (A) The two organizers are positioned in a single blastoderm. The left and right sides of each twin are indicated. Note that the left side of the primary twin is across from the right side of the induced twin. (B) The cells of this blastoderm are oriented by polarity proteins (orange arrows) including planar cell polarity and apical basal polarity proteins. These polarity proteins are themselves oriented with respect to the anterior-posterior and dorsal-ventral axes, as described previously (Vandenberg and Levin, 2012). Within this highly organized blastoderm, both gap junctions (green cylinders) and small signaling molecules like 5-HT (purple stars) are required for proper $L R$ patterning in the induced twin. Two roles for 5-HT are proposed. (C) One hypothesis is that 5-HT maintains subcellular asymmetries, providing an amplification of the asymmetries established by the polarity proteins. Thus, each cell in the blastoderm, or perhaps only specific cells in a late $L R$ "organizer," has its own physiological and biochemical $L R$ axis. (D) The second hypothesis is that a surge of 5-HT at a specific time, and perhaps again only in specific cells in a late $L R$ "organizer," are sufficient to induce consistent $L R$ gene expression. Thus, asymmetric expression is not required, but a temporal pulse is needed. 
involves subcellular asymmetric distribution of 5-HT within specific "organizer" cells, which reinforces the LR information established by polarity proteins (Fig. 6C). The second involves time-dependent flux of 5-HT (Fig. 6D), which induces the expression of downstream genes, similar to the role of $5-\mathrm{HT}$ in the early embryo (Carneiro et al., 2011) and the role of neurotransmitters in signaling in the central nervous system during information processing. Future work will test these hypotheses; thus, the exact role of 5-HT in conjoined twins remains to be elucidated.

Several of the tools we employed in these studies provided us with spatial and/or temporal control of reagents, which enabled us to determine which cells are involved in LR patterning of late induced organizers and at what point in development specific mechanisms must be present. Just as previous studies have shown that localization of 5-HT to blastomeres that are not on the ventral right side of the embryo can disrupt LR patterning and inhibition of 5-HT signaling on the right side induces heterotaxia (Fukumoto et al., 2003; Fukumoto et al., 2005a; Fukumoto et al., 2005b; Rea et al., 2013; Vandenberg et al., 2013b), here we have used caged serotonin molecules to show that abnormal expression of 5-HT as late as stage 10 randomized LR patterning in conjoined twins (Fig. 4). Randomized LR axes were observed when reagents were targeted to the entire embryo (1-cell injection of caged 5-HT), to the primary twin (dorsal injections of $\mathrm{H} 7$ ), or to the induced twin (ventral injections of caged 5-HT and ventral injections of ABP), consistent with the need for embryo-wide transfer of serotoninmediated instructive information during late LR patterning.

Our current and previous work implicates a number of physiological pathways involved in the establishment of the LR axis, both in wild type embryos and in induced twins. In regulating the cell behavior that gives rise to asymmetric organogenesis, these pathways must affect gene expression. As a first step in identifying transcriptional targets functioning earlier than Nodal (in addition to the epigenetic silencing previously characterized (Carneiro et al., 2011)), and to test our hypothesis that asymmetric transcription begins prior to appearance of the ciliated node, we performed a microarray analysis comparing the right and left halves of stage 13 embryos and identified 401 transcripts exhibiting a lateralized expression bias. As noted previously for asymmetric maternal proteins (Levin et al., 2002; Qiu et al., 2005; Adams et al., 2006; Lobikin et al., 2012a), the lateralized transcripts were much more heavily associated with the right side. Overall, these genes represent a number of diverse families, many of which have not been previously implicated in the specification of LR asymmetry. In situ hybridization for collagen9a2, a transcript identified as expressed on the left side only by the genechip, corroborated the microarray data, showed strongly left biased expression in all of the embryos examined. This result is exciting, as both GJC and 5-HT have been shown to affect collagen synthesis in other model systems (Highton and Garrett, 1963; Kasho et al., 1998; Moyer et al., 2004; Ehrlich et al., 2006; Young et al., 2009). Moreover, collagen is already implicated in LR patterning of structures in C. elegans (Bergmann et al., 1998) and chick (Trelstad and Coulombre, 1971), confirming the deep conservation of LR mechanisms among diverse phyla that was recently shown using tubulin modifications (Lobikin et al., 2012a). While future studies will probe the functional roles of these asymmetric transcripts in the causal chain leading from asymmetric physiology to left-sided genes such as Nodal, our results are consistent with prior studies indicating that molecular asymmetry is established very early during development and is not limited to maternal protein (Danilchik et al., 2006; Lobikin et al., 2012a).

\section{Conclusions}

We have used the conjoined twin model to examine the mechanisms involved in orienting the LR axis in a late-induced organizer. The data reveal that both GJC and 5-HT signaling are required for this instructive influence, but that potassium and proton efflux is not, and that a number of interesting genes are asymmetrically transcribed during these timepoints, prior to initiation of ciliary flow. Our previous studies of conjoined twins revealed a role for polarity proteins, including apical-basal and planar cell polarity proteins, in the orientation of the LR axis (Vandenberg and Levin, 2012). We propose a model whereby the polarity proteins align the cells in the blastoderm, enabling signaling molecules, including $5-\mathrm{HT}$, to pass through a series of open gap junctions from the primary to the secondary organizer. Both GJC and 5-HT are required for proper orientation of the LR axis in late-induced Xenopus organizers, consistent with results from other species that orient this axis in the context of large numbers of cells. One of the key avenues for future work will be to mechanistically dissect the role of these early mechanisms in propagating the initial cytoskeleton-derived asymmetry information to organizers induced in fields of thousands of small cells.

\section{Materials and Methods}

\section{Animal rearing}

Xenopus laevis embryos were collected and fertilized in vitro following standard protocols (Sive et al., 2000). Embryos were maintained in $0.1 \mathrm{x}$ Modified Marc's Ringers (MMR) pH 7.8 at $14-20^{\circ} \mathrm{C}$ in laboratory incubators and staged according to (Nieuwkoop and Faber, 1967). All experiments were approved by the Animal Care and Use Committee at Tufts University and were conducted according to the Guidelines for the Care and Use for Laboratory Animals.

\section{Microarray}

At Nieuwkoop and Faber stage 13, embryos were bisected into right and left halves with a scalpel, transferred into separate Eppendorf microcentrifuge tubes, and immediately frozen at $-80^{\circ} \mathrm{C}$. A total of 50 embryos, resulting from a combination of eggs from three mothers, were pooled for analysis. Only embryos with completely normal external development were used. RNA extraction and microarray analysis were performed by the Beth Israel Deaconess Medical Center Genomics Core using a GeneChip Xenopus laevis genome 2.0 array (Affymetrix, Santa Clara, CA) following the standard Affymetrix protocol. Following expression analysis, a database was built from all resulting transcription levels comparing the right and left embryo samples. From this database, individual genes were removed if reported expression levels were not above those of background levels for the genechip, as were any genes which did not show at least a 2-fold increase vs. that of the opposite side.

\section{Microinjection of molecular constructs}

For induction of conjoined twins, XSiamois mRNA was injected into a left ventral vegetal blastomere at the 8- or 16-cell stage (Nascone and Mercola, 1997). Only twins with two fully developed hearts and mostly complete heads, were used in these experiments (Vandenberg and Levin, 2012). Incomplete twins, including those with microcephaly and abnormal notochord extension, were assessed separately to ensure that slight anterior-posterior or dorsal-ventral defects that could not be detected in the complete twins were not confounding results. No differences were observed in complete 
versus incomplete twins for any treatment.

A number of additional molecular constructs were used in these experiments including amine binding protein (ABP), a protein that binds, sequesters and inactivates 5-HT (Fukumoto et al., 2005b), and H7, a dominant negative form of a chimeric connexin that disrupts GJC in Xenopus (Paul et al., 1995; Levin and Mercola, 1998). For all microinjections of mRNA constructs, capped synthetic mRNAs (Sive et al., 2000) were dissolved in water containing a lineage tracer and injected into embryos in $3 \%$ Ficoll using standard methods (50-100 msec pulses with borosilicate glass needles calibrated for a bubble pressure of $50-70 \mathrm{kPa}$ in water). Volumes of 2-7 nl were injected per blastomere for all constructs. Injections were performed at the specified stage and were typically targeted to specific blastomeres. All injections were tested in at least 3 different mothers on at least 2 different days.

The Xenopus oocyte is a standard model for expressing exogenous proteins (such as ion channels) via mRNA microinjection. To verify that our in vitro transcribed mRNA was intact and resulted in the production of functional proteins, in a small subset of experiments, mRNA encoding $\beta$ galactosidase ( $\beta$-gal) was co-injected with other mRNAs in embryos where twins were induced. Embryos were fixed at gastrula or neurula stages, washed, and stained with X-gal (Roche Applied Sciences, Indianapolis, IN) at $37^{\circ} \mathrm{C}$. $\beta$-gal was observed in gastrula and neurula stages with different expression patterns depending on where injections were localized (see Supplementary Fig. S1).

\section{Drug and chemical treatment}

Xenopus embryos were treated with chemical reagents that have previously been demonstrated to affect LR patterning (Table 1). Embryos were split into three batches: untreated controls, early treatments, and late treatments. Early treatment embryos were exposed to a single chemical from 1-cell through neurula stages (Nieuwkoop \& Faber stages 19-22). Late treatment embryos were maintained in $0.1 \times$ MMR until stage 8 , when they were transferred to fresh solutions containing a single chemical. These embryos were maintained in the chemical until neurula stages, then washed repeatedly in $0.1 \mathrm{x}$ MMR and housed in clean $0.1 \mathrm{x}$ MMR until stage 45 . Concentrations previously identified as effective were tested, as well as higher and lower concentrations, to determine the most effective concentration at disrupting LR patterning without excessive toxicity (determined by mortality and other defects not related to LR patterning.) Only concentrations with toxicity $<20 \%$ were used in these experiments.

\section{Drug and chemical treatment of conjoined twins}

Following the injection of XSiamois at the 8- or 16-cell stage, embryos were maintained in $0.1 \times$ MMR until stage 8 , and then transferred to fresh solutions containing effective concentrations of each chemical. Embryos were incubated in the chemical until neurula stages, then washed repeatedly in 0.1x MMR and maintained in clean 0.1x MMR until stage 45. Concentrations are indicated in Table 1. All drugs/chemicals were tested in at least 2 different batches with embryos from at least 3 different mothers.

\section{Caged serotonin}

One group of embryos was injected with approximately $50 \mathrm{ng} \mathrm{BHQ-}$ $0-5 \mathrm{HT}$ at the 1-cell stage, and a subset of this group was injected with XSiamois mRNA at the 8- to 16-cell stage. A second group of embryos was

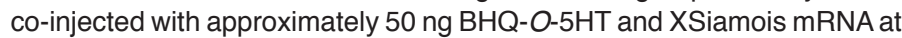
the 8- to 16-cell stage. All injections were performed under dark conditions and embryos were housed in 0.1x MMR in the dark. Embryos injected with $\mathrm{BHQ}-\mathrm{O}-5 \mathrm{HT}$ were exposed to a broad spectrum lamp for one hour starting at the 32 -cell stage, stage 8 or at stage 10 to uncage the molecule and release 5-HT (Rea et al., 2013); these embryos were then returned to the dark for the remainder of the experiment.

\section{Laterality assay}

At stage 45, singleton embryos were analyzed for position (situs) of the heart, stomach, and gall bladder according to (Levin and Mercola, 1998).
Heterotaxia was defined as the reversal in position of one or more organs. Only embryos with a normal dorso-anterior index (DAI 5) were scored to prevent confounding of randomization caused by midline defects (Danos and Yost, 1995). Conjoined twins were also analyzed at stage 45 for situs of the heart for both twins and situs of the shared stomach and gall bladder (Vandenberg and Levin, 2010a). Because of the abnormal position of the heart in some twins, situs was always scored when the heart was beating to allow definitive determination of the heart orientation. For both singleton embryos and conjoined twins, percent heterotaxia was calculated as the absolute number of heterotaxic tadpoles divided by the total number of scorable tadpoles. A Chi Square test with Pearson correction for increased stringency was used to compare absolute counts of heterotaxic embryos in control and treated groups.

\section{In situ hybridization}

Whole mount in situhybridization was performed using standard protocols (Harland, 1991) embryos were fixed at stage 12 and 13. Embryos were washed in phosphate buffered saline $+0.1 \%$ Tween-20, and transferred through a $25 \% / 50 \% / 75 \% / 100 \%$ methanol series. Chromogenic reaction times varied to maximize signal to background ratios. For the control (i.e. non-lateralized) antisense probe Slug (European Xenopus resource center pMX363 Xslug) chromogenic development required $3 \mathrm{~h}$ at $37^{\circ} \mathrm{C}$ while the experimental antisense probe Col9a2 (NCBI accession \# BC091722) required $9 \mathrm{~h}$ at $37^{\circ} \mathrm{C}$.

\section{Acknowledgements}

The authors gratefully acknowledge Amber Brand, Erin Switzer, and Amanda Allen for Xenopus husbandry, and Joan Lemire for assistance with molecular techniques. In addition we would like to acknowledge Manoj Bhasin and Marie Bruno-Joseph forperforming microarray services. We also thank other members of the Levin Laboratory for helpful discussions about this work. This research was funded by the American Heart Association Established Investigator grant 0740088N and NIH grants R01-GM077425 (to ML) and R01 NS070159 (to TMD), NSF grants CHE-1012412 and CHE1317760 (to TMD), and NRSA grant 1F32GM087107 (to LNV).

\section{References}

ADAMS, D. S. and LEVIN, M. (2006). Inverse drug screens: a rapid and inexpensive method for implicating molecular targets. Genesis 44: 530-540.

ADAMS, D. S., ROBINSON, K. R., FUKUMOTO, T., YUAN, S., ALBERTSON, R. C., YELICK, P., KUO, L., MCSWEENEY, M. and LEVIN, M. (2006). Early, H+-VATPase-dependent proton flux is necessary for consistent left-right patterning of non-mammalian vertebrates, Development 133: 1657-1671.

ANDERSEN, J. F., FRANCISCHETTI, I. M., VALENZUELA, J. G., SCHUCK, P. and RIBEIRO, J. M. (2003). Inhibition of hemostasis by a high affinity biogenic amine-binding protein from the saliva of a blood-feeding insect. $J$ Biol Chem 278: 4611-4617.

ARMAKOLAS, A. and KLAR, A. J. (2007). Left-right dynein motor implicated in selective chromatid segregation in mouse cells. Science 315: 100-101.

ARMAKOLAS, A., KOUTSILIERIS, M. and KLAR, A. J. (2010). Discovery of the mitotic selective chromatid segregation phenomenon and its implications for vertebrate development. Curr Opin Cell Biol 22: 81-87.

AW, S., ADAMS, D. S., QIU, D. and LEVIN, M. (2008). H, K-ATPase protein localization and Kir4.1 function reveal concordance of three axes during early determination of left-right asymmetry. Mech Dev 125: 353-372.

AW, S., KOSTER, J., PEARSON, W., NICHOLS, C., SHI, N. Q., CARNEIRO, K. and LEVIN, M. (2010). The ATP-sensitive K(+)-channel (K(ATP)) controls early left-right patterning in Xenopus and chick embryos. Dev Biol 346: 39-53.

AW, S. and LEVIN, M. (2008). What's left in asymmetry. Dev Dyn 237: 3453-3463.

BASU, B. and BRUECKNER, M. (2008). Cilia: multifunctional organelles at the center of vertebrate left-right asymmetry. Curr Top Dev Biol 85: 151-174.

BERGMANN, D. C., CREW, J. R., KRAMER, J. M. and WOOD, W. B. (1998). Cuticle chirality and body handedness in Caenorhabditis elegans. Dev. Genet. 23: 164-174 
BEYER, T., DANILCHIK, M., THUMBERGER, T., VICK, P., TISLER, M., SCHNEIDER, I., BOGUSCH, S., ANDRE, P., ULMER, B., WALENTEK, P. etal., (2012). Serotonin signaling is required for Wnt-dependent GRP specification and leftward flow in Xenopus. Curr Biol 22: 33-39.

BLUM, M., BEYER, T., WEBER, T., VICK, P., ANDRE, P., BITZER, E. and SCHWEICKERT, A. (2009). Xenopus, an ideal model system to study vertebrate left-right asymmetry. Dev Dyn 238: 1215-1225.

BROWN, N. A. and WOLPERT, L. (1990). The development of handedness in left/ right asymmetry. Development 109: 1-9.

BUNNEY, T. D., DE BOER, A. H. and LEVIN, M. (2003). Fusicoccin signaling reveals 14-3-3 protein function as a novel step in left-right patterning during amphibian embryogenesis. Development 130: 4847-4858.

BURDINE, R. D. and CASPARY, T. (2013). Left-right asymmetry: lessons from Cancun. Development 140: 4465-4470.

CARNEIRO, K., DONNET, C., REJTAR, T., KARGER, B. L., BARISONE, G. A., DIAZ, E., KORTAGERE, S., LEMIRE, J. M. and LEVIN, M. (2011). Histone deacetylase activity is necessary for left-right patterning during vertebrate development. $B M C$ Dev Biol 11: 29

CASEY, B. and HACKETT, B. P. (2000). Left-right axis malformations in man and mouse. Curr. Opin. Genet. Dev. 10: 257-261.

CHEN, Y., MIRONOVA, E., WHITAKER, L. L., EDWARDS, L., YOST, H. J. and RAMSDELL, A. F. (2004). ALK4 functions as a receptor for multiple TGF betarelated ligands to regulate left-right axis determination and mesoderm induction in Xenopus. Dev Biol 268: 280-294.

COHEN, M. S., ANDERSON, R. H., COHEN, M. I., ATZ, A. M., FOGEL, M., GRUBER, P. J., LOPEZ, L., ROME, J. J. and WEINBERG, P. M. (2007). Controversies, genetics, diagnostic assessment, and outcomes relating to the heterotaxy syndrome. Cardiol Young 17 Suppl 2: 29-43.

DANILCHIK, M. V., BROWN, E. E. and RIEGERT, K. (2006). Intrinsic chiral properties of the Xenopus egg cortex: an early indicator of left-right asymmetry? Development 133: 4517-4526.

DANOS, M. C. and YOST, H. J. (1995). Linkage of cardiac left-right asymmetry and dorsal-anterior development in Xenopus. Development 121: 1467-1474.

EHRLICH, H. P., SUN, B., SAGGERS, G. C. and KROMATH, F. (2006). Gap junction communications influence upon fibroblast synthesis of Type I collagen and fibronectin. J. Cell. Biochem. 98: 735-743.

FUKUMOTO, T., BLAKELY, R. and LEVIN, M. (2005a). Serotonin transporter function is an early step in left-right patterning in chick and frog embryos. Dev Neurosci 27: 349-363.

FUKUMOTO, T., KEMA, I., NAZARENKO, D. and LEVIN, M. (2003). Serotonin is a novel very early signaling mechanism in left-right asymmetry. Dev. Biol. 259: 490.

FUKUMOTO, T., KEMA, I. P. and LEVIN, M. (2005b). Serotonin signaling is a very early step in patterning of the left-right axis in chick and frog embryos. Curr Biol 15: 794-803.

GUAN, X. and RUCH, R. (1996). Gap junction endocytosis and lysosomal degradation of connexin43-P2 WB-F344 rat liver epithelial cells treated with DDT and lindane. Carcinogenesis 17: 1791-1798.

HACKETT, B. P. (2002). Formation and malformation of the vertebrate left-right axis. Curr Mol Med 2: 39-66.

HARLAND, R. M. (1991) In situ hybridization: an improved whole mount method for Xenopus embryos. in B. K. Kay and H. B. Peng (eds.) Xenopus laevis: Practical uses in cell and molecular biology, vol. 36. San Diego: Academic Press.

HEACOCK, A. M. and AGRANOFF, B. W. (1977). Clockwise growth of neurites from retinal explants. Science 198: 64-66.

HIGHTON, T. C. and GARRETT, M. H. (1963). Some effects of serotonin and related compounds on human collagen. Lancet 1: 1234-1237.

HYATT, B. A. and YOST, H. J. (1998). The left-right coordinator: the role of Vg1 in organizing left-right axis formation. Cell 93: 37-46.

KASHO, M., SAKAI, M., SASAHARA, T., ANAMI, Y., MATSUMURA, T., TAKEMURA, T., MATSUDA, H., KOBORI, S. and SHICHIRI, M. (1998). Serotonin enhances the production of type IV collagen by human mesangial cells. Kidney Int. 54: 1083-1092.

KLAR, A. J. (1994). A model for specification of the left-right axis in vertebrates. Trends Genet 10: 392-396.

KLAR, A. J. (2008). Support for the selective chromatid segregation hypothesis advanced for the mechanism of left-right body axis development in mice. Breast Dis 29: 47-56.
KRAMER, K. L., BARNETTE, J. E. and YOST, H. J. (2002). PKCgamma regulates syndecan-2 inside-out signaling during Xenopus left-right development. Cell 111: 981-990.

KUTZ, K. (1993). Pharmacology, toxicology and human pharmacokinetics of tropisetron. Ann Oncol 4 Suppl 3: 15-18.

LEVIN, M. (2003). Hypothesis: motor proteins and ion pumps, not ciliary motion, initiate LR asymmetry. Bioessays 25: 1002-1010.

LEVIN, M. (2006). Is the early left-right axis like a plant, a kidney, or a neuron? The integration of physiological signals in embryonic asymmetry. Birth Defects Res C Embryo Today 78: 191-223.

LEVIN, M., JOHNSON, R. L., STERN, C. D., KUEHN, M. and TABIN, C. (1995). A molecular pathway determining left-right asymmetry in chick embryogenesis. Cell 82: 803-814.

LEVIN, M. and MERCOLA, M. (1998). Gap junctions are involved in the early generation of left-right asymmetry. Dev Biol 203: 90-105.

LEVIN, M. and MERCOLA, M. (1999). Gap junction-mediated transfer of left-right patterning signals in the early chick blastoderm is upstream of Shh asymmetry in the node. Development 126: 4703-4714.

LEVIN, M. and NASCONE, N. (1997). Two molecular models of initial left-right asymmetry generation. Medical Hypotheses 49: 429-435.

LEVIN, M., ROBERTS, D., HOLMES, L. and TABIN, C. (1996). Laterality defects in conjoined twins. Nature 384: 321.

LEVIN, M., THORLIN, T., ROBINSON, K. R., NOGI, T. and MERCOLA, M. (2002). Asymmetries in $\mathrm{H}+/ \mathrm{K}+-$ ATPase and cell membrane potentials comprise a very early step in left-right patterning. Cell 111: 77-89.

LI, R. and MATHER, J. (1997). Lindane, an inhibitor of gap junction formation, abolishes oocyte directed follicle organizing activity in vitro. Endocrinology 138: 4477-4480.

LOBIKIN, M., WANG, G., XU, J., HSIEH, Y. W., CHUANG, C. F., LEMIRE, J. M. and LEVIN, M. (2012a). Early, nonciliary role for microtubule proteins in left-right patterning is conserved across kingdoms. Proc. Natl. Acad. Sci. USA 109: 12586-12591.

LOBIKIN, M., WANG, G., XU, J., HSIEH, Y. W., CHUANG, C. F., LEMIRE, J. M. and LEVIN, M. (2012b). Early, nonciliary role for microtubule proteins in left-right patterning is conserved across kingdoms. Proc NatlAcad Sci U SA 109: 12586-12591.

MONGE, A., PALOP, J. A., DEL CASTILLO, J. C., CALDERO, J. M., ROCA, J., ROMERO, G., DEL RIO, J. and LASHERAS, B. (1993). Novel antagonists of 5-HT3 receptors. Synthesis and biological evaluation of piperazinylquinoxaline derivatives. J Med Chem 36: 2745-2750.

MOROKUMA, J., BLACKISTON, D. and LEVIN, M. (2008). KCNQ1 and KCNE1 K+ channel components are involved in early left-right patterning in Xenopus laevis embryos. Cell Biochem Biophys 21: 357-372.

MOYER, K. E., SAGGERS, G. C. and EHRLICH, H. P. (2004). Mast cells promote fibroblast populated collagen lattice contraction through gap junction intercellular communication. Wound Repair Regen. 12: 269-275.

MUDERS, K., FISCHER, A. and BLUM, M. (2006). Gap junctions mediate asymmetric gene expression in rabbit embryos. Dev Biol 295: 450-451.

NASCONE, N. and MERCOLA, M. (1997). Organizer induction determines left-right asymmetry in Xenopus. Dev Biol 189: 68-78.

NIEUWKOOP, P. D. and FABER, J. (1967) Normal table of Xenopus laevis (Daudin), Amsterdam: North-Holland Publishing Company.

OVIEDO, N. J. and LEVIN, M. (2007). Gap junctions provide new links in left-right patterning. Cell 129: 645-647.

PALMER, A. R. (1996). From symmetry to asymmetry: phylogenetic patterns of asymmetry variation in animals and their evolutionary significance. Proc Natl Acad Sci USA 93: 14279-14286.

PALMER, A. R. (2004). Symmetry breaking and the evolution of development. Science 306: 828-833.

PAUL, D., YU, K., BRUZZONE, R., GIMLICH, R. and GOODENOUGH, D. (1995). Expression of a dominant negative inhibitor of intercellular communication in the early Xenopus embryo causes delamination and extrusion of cells. Development 121: $371-381$

PEETERS, H. and DEVRIENDT, K. (2006). Human laterality disorders. Eur J Med Genet 49: 349-362.

QIU, D., CHENG, S. M., WOZNIAK, L., MCSWEENEY, M., PERRONE, E. and LEVIN, M. (2005). Localization and loss-of-function implicates ciliary proteins in early, cytoplasmic roles in left-right asymmetry. Dev Dyn 234: 176-189. 
REA, A. C., VANDENBERG, L. N., BALL, R. E., SNOUfFER, A. A., HUdSON, A., ZHU, Y., MCLAIN, D. E., JOHNSTON, L. L., LAUDERDALE, J. D., LEVIN, M. et al., (2013). Light activated serotonin for exploring its action in biological systems. Chem. Biol. 20: 1536-1546.

SAUER, S. and KLAR, A. J. (2012). Left-right symmetry breaking in mice by left-right dynein may occur via a biased chromatid segregation mechanism, without directly involving the Nodal gene. Front. Oncol. 2: 166.

SCHWEICKERT, A., WEBER, T., BEYER, T., VICK, P., BOGUSCH, S., FEISTEL, K. and BLUM, M. (2007). Cilia-driven leftward flow determines laterality in Xenopus. Curr Biol 17: 60-66

SIVE, H., GRAINGER, R. M. and HARLAND, R. (2000) Early development of Xenopus laevis, New York: Cold Spring Harbor Laboratory Press.

SUPP, D. M., WITTE, D. P., POTTER, S. S. and BRUECKNER, M. (1997). Mutation of an axonemal dynein affects left-right asymmetry in inversus viscerum mice. Nature 389: 963-966.

TABIN, C. J. (2011). Establishing robust left-right asymmetry in the vertebrate embryo. Dev Cell 20: e2.

TRELSTAD, R. L. and COULOMBRE, A. J. (1971). Morphogenesis of the collagenous stroma in the chick cornea. J. Cell. Biol. 50: 840-858.

VANDENBERG, L. N., LEMIRE, J. M. and LEVIN, M. (2013a). It's never too early to get it right: a conserved role for the cytoskeleton in left-right asymmetry. Commun Integr Biol 6: e27155.

VANDENBERG, L. N., LEMIRE, J. M. and LEVIN, M. (2013b). Serotonin has early, cilia-independent roles in Xenopusleft-right patterning. Dis ModelMech6:261-268.

VANDENBERG, L. N. and LEVIN, M. (2010a). Consistent left-right asymmetry cannot be established by late organizers in Xenopus unless the late organizer is a conjoined twin. Development 137: 1095-1105.

VANDENBERG, L. N. and LEVIN, M. (2010b). Far from solved: a perspective on what we know about early mechanisms of left-right asymmetry. Dev Dyn239:3131-3146.

VANDENBERG, L. N. and LEVIN, M. (2012). Polarity proteins are required for left-right axis orientation and twin-twin instruction. Genesis 50: 219-234.

VANDENBERG, L. N. and LEVIN, M. (2013). A unified model for left-right asymmetry? Comparison and synthesis of molecular models of embryonic laterality. Dev Biol 379: 1-15. (doi: 10.1016/j.ydbio.2013.03.021).

VANDENBERG, L. N., MORRIE, R. D., SEEBOHM, G., LEMIRE, J. M. and LEVIN, M. (2013c). Rab GTPases are required for early orientation of the left-right axis in Xenopus. Mech Dev 130: 254-271.

VICK, P., SCHWEICKERT, A., WEBER, T., EBERHARDT, M., MENCL, S., SHCHERBAKOV, D., BEYER, T. and BLUM, M. (2009). Flow on the right side of the gastrocoel roof plate is dispensable for symmetry breakage in the frog Xenopus laevis. Dev. Biol. 331: 281-291.

WALENTEK, P., BEYER, T., THUMBERGER, T., SCHWEICKERT, A. and BLUM, M. (2012). ATP4a is required for Wnt-dependent Foxj1 expression and leftward flow in Xenopus left-right development. Cell Rep. In press. DOI:10.1016/j.celrep.2012.03.005.

YOST, H. J. (1990). Inhibition of proteoglycan synthesis eliminates left-right asymmetry in Xenopus laevis cardiac looping. Development 110: 865-874.

YOST, H. J. (1998). Left-right development in Xenopus and zebrafish. Sem. Cell Dev. Biol. 9: 61-66.

YOUNG, N. J., BECKER, D. L., FLECK, R. A., GOODSHIP, A. E. and PATTERSONKANE, J. C. (2009). Maturational alterations in gap junction expression and associated collagen synthesis in response to tendon function. Matrix Biol 28: 311-323. 


\section{Further Related Reading, published previously in the Int. J. Dev. Biol.}

Unraveling new roles for serotonin receptor 2B in development: key findings from Xenopus Michela Ori, Stefania De Lucchini, Giulia Marras and Irma Nardi

Int. J. Dev. Biol. (2013) 57: 707-714

Connexins: a junctional crossroad to breast cancer

Jamal A. El-Saghir, Elia T. El-Habre, Marwan E. El-Sabban and Rabih S. Talhouk

Int. J. Dev. Biol. (2011) 55: 773-780

Molecular tools, classic questions - an interview with Clifford Tabin

Michael K. Richardson

Int. J. Dev. Biol. (2009) 53: 725-731

Lef1 plays a role in patterning the mesoderm and ectoderm in Xenopus tropicalis

Giulietta Roël, Yoony Y.J. Gent, Josi Peterson-Maduro, Fons J. Verbeek and Olivier Destrée Int. J. Dev. Biol. (2009) 53: 81-89

Regulation and function of Spalt proteins during animal development Jose F. de Celis and Rosa Barrio

Int. J. Dev. Biol. (2009) 53: 1385-1398

Expression of complement components coincides with early patterning and organogenesis in Xenopus laevis

Valérie A. McLin, Cheng-Hui Hu, Rina Shah and Milan Jamrich

Int. J. Dev. Biol. (2008) 52: 1123-1133

Serotonin involvement in the metamorphosis of the hydroid Eudendrium racemosum Giuliana Zega, Roberta Pennati, Arianna Fanzago and Fiorenza De Bernardi Int. J. Dev. Biol. (2007) 51: 307-313

The roles of activin and follistatin signaling in chick gastrulation.

M Levin

Int. J. Dev. Biol. (1998) 42: 553-559

5 yr ISI Impact Factor $(2011)=2.959$
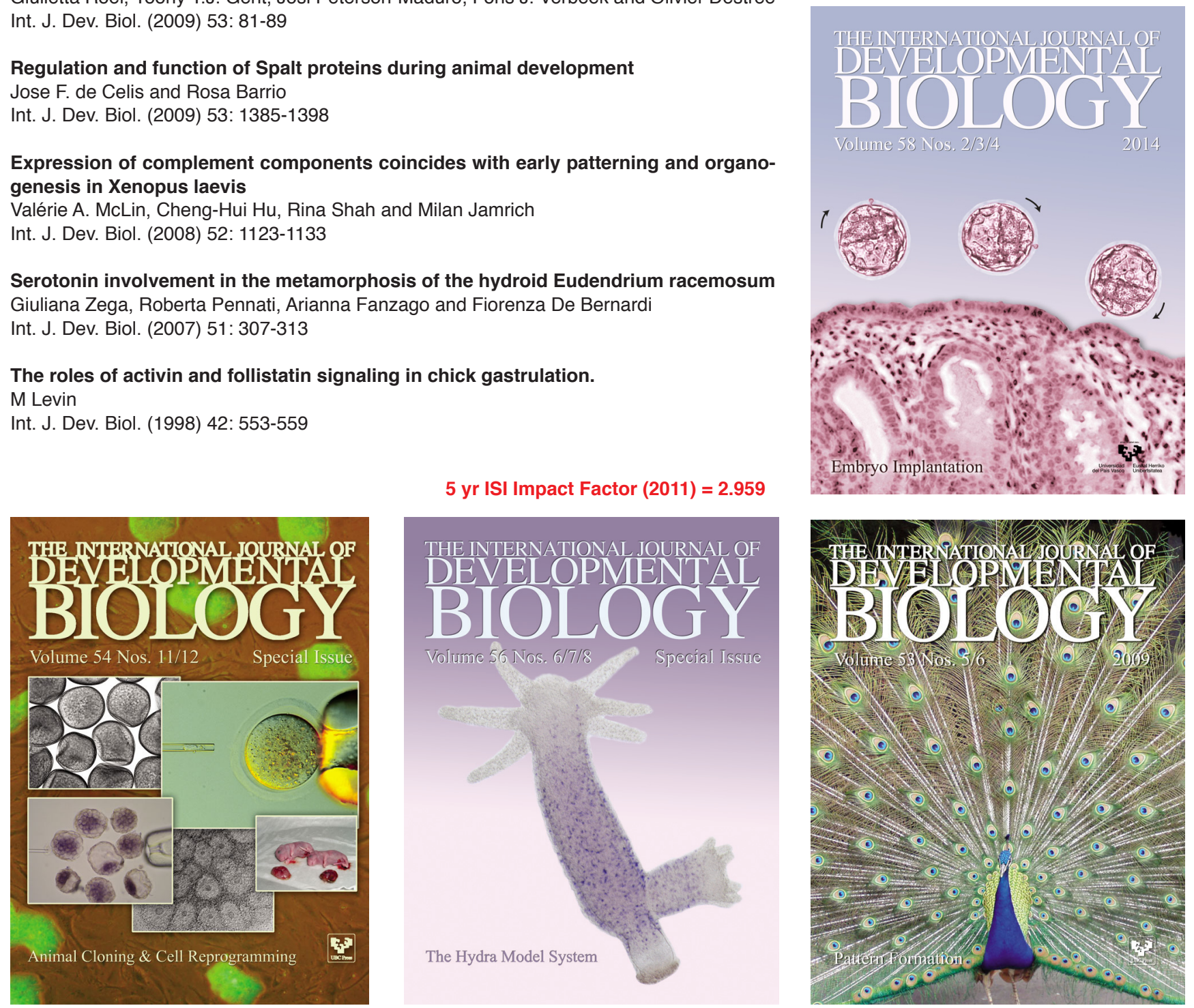